\title{
Waiting for coronary revascularization: A comparison between New York State, the Netherlands and Sweden
}

\author{
Steven J. Bernstein ${ }^{\mathrm{a}, \mathrm{b}, *}$, Henk Rigter ${ }^{\mathrm{c}, \mathrm{d}}$, Bengt Brorsson ${ }^{\mathrm{e}}$, \\ Lee H. Hilborne ${ }^{\text {f,g }}$, Lucian L. Leape ${ }^{\mathrm{g}, \mathrm{h}}$, Annejet P. Meijler ${ }^{\mathrm{c}}$, \\ Jan K. Scholma ${ }^{\mathrm{c}}$, Ann-Sofie Nord ${ }^{\mathrm{e}}$ \\ a Departments of Medicine and Health Management and Policy, University of Michigan, \\ 3116 Taubman Center, Ann Arbor, MI 48109-0376, USA \\ ${ }^{\mathrm{b}}$ Veterans Affairs Center for Practice Management and Outcomes Research, P.O. Box 130170, \\ Ann Arbor, MI 48113, USA \\ ' Institutes for Medical Technology Assessment, and of Public Health and Social Medicine, \\ Erasmus University, Rotterdam, The Netherlands \\ d Netherlands Institute of Mental Health and Addiction, Utrecht, The Netherlands \\ ${ }^{\mathrm{e}}$ The Swedish Council on Technology Assessment in Health Care, Stockholm, Sweden \\ ${ }^{\mathrm{f}}$ Departments of Medicine and Pathology and Laboratory Medicine, University of California, \\ Los Angeles, CA, USA \\ ${ }^{\mathrm{g}}$ RAND Corporation, 1700 Main Street, Santa Monica, CA 90406, USA \\ ${ }^{\mathrm{h}}$ Department of Health Policy and Management, Harvard School of Public Health, \\ 677 Huntington Avenue, Boston, MA 02115, USA
}

Received 15 May 1997; accepted 3 June 1997

\begin{abstract}
Objective: To compare waiting times for percutaneous transluminal coronary angioplasty (PTCA) and coronary artery bypass graft (CABG) surgery in New York State, the Netherlands and Sweden and to determine whether queuing adversely affects patients' health. Methods: We reviewed the medical records of 4487 chronic stable angina patients who underwent PTCA or CABG in one of 15 New York State hospitals $(n=1021)$ or were referred for PTCA or CABG to one of ten hospitals in the Netherlands $(n=1980)$ or to one of seven hospitals in Sweden $(n=1486)$. We measured the median waiting time between coronary angiography and PTCA or CABG. Results: The median waiting time for PTCA in
\end{abstract}

* Corresponding author. At the University of Michigan. Tel: + 1313 9364787; Fax: + 13139368944.

0168-8510/97/\$17.00 C 1997 Elsevier Science Ireland Ltd. All rights reserved.

PII S 0168-8510(97)00039-0 
New York was 13 days compared with 35 and 42 days, respectively, in the Netherlands and Sweden $(P<0.001)$. For CABG, New York patients waited 17 days, while Dutch and Swedish patients waited 72 and 59 days, respectively $(P<0.001)$. The Swedish and Dutch waiting list mortality rate was $0.8 \%$ for CABG candidates and $0.15 \%$ for PTCA candidates. Conclusions: There were large variations in waiting time for coronary revascularization among these three sites. Patients waiting for CABG were at greatest risk of experiencing an adverse event. In both the Netherlands and Sweden, the capacity to perform coronary revascularization has been expanded since this study began. Further international cooperation may identify other areas where quality of care can be improved. (C) 1997 Elsevier Science Ireland Ltd.

Keywords: Coronary artery bypass graft surgery; Percutaneous transluminal coronary angioplasty; Quality of health care; Health policy; Waiting list

\section{Introduction}

Coronary artery disease is a major cause of death and morbidity in the Western World. Although our ability to treat coronary artery disease with coronary artery bypass graft surgery (CABG) and percutaneous transluminal coronary angioplasty (PTCA) has improved with time, both are complex and expensive procedures, and these procedures have been closely regulated in many locales. This regulation has often focused on limiting the number of interventional cardiothoracic centers in order to increase procedural volume and decrease complications and cost per procedure [1-5]. An issue that has not been well examined is whether such regulation limits access to these services. Excessive delays in access may decrease the quality of care. Conversely, if treatment capacity is such that everyone can be treated immediately, some have argued that there may be a tendency to increase the use of resources by expanding the indications for these procedures beyond what is supported by the literature [6,7]. The optimal situation maybe in between, with active management of access to high technology services such as CABG and PTCA providing efficient use of these services without affecting quality of care [8].

Active management, which usually limits access by some means of rationing, occurs in countries with both universal and non-universal health care systems. In the United States, a country without universal health care, one frequently sees implicit rationing with insured patients having ready access to care while uninsured patients are denied access or receive delayed care [9]. In Canada and Western Europe, where patients have universal access to care, a more visible form of rationing occurs through the use of waiting lists [8,10-12]. There have been few comparative studies on the outcome of care provided through such systems. As the United States moves towards managed care and some European countries try to add free market policies to their national health insurance systems, understanding the consequences of these different means of restricting access takes on added importance. 
We report here on the waiting time for chronic stable angina patients undergoing either PTCA or CABG in New York State, Sweden and the Netherlands. We assess the frequency of major adverse events among the Swedish and Dutch patients. By focusing on patients with a relatively homogeneous clinical condition, this approach reduces the bias of cross-national differences in the types of patients referred for these procedures. The inclusion of patients from a representative sample of cases at these three sites suggests that the results are generalizable.

\section{Methods}

\subsection{Patient populations}

We examined waiting times from coronary angiography to PTCA and CABG in New York State, Sweden and the Netherlands. These data were originally collected to assess the appropriateness of use of PTCA and CABG at each of these sites [13-16]. In order to assure that differences in waiting time reflected differences in styles of practice (e.g., urgency of the procedure) and not differences in the type of patients undergoing the procedure (e.g., the proportion of patients presenting with unstable angina vs. chronic stable angina vs. acute myocardial infarction) we restricted these analyses to one group of patients present in all three datasets, chronic stable angina patients who had not previously undergone bypass surgery. The definition of chronic stable angina was the same at all three sites.

In New York State, we obtained data on 2694 patients randomly sampled from 15 New York State hospitals who underwent PTCA or CABG in 1990 [13,15]. For this report we excluded all patients who presented with conditions other than chronic stable angina $(n=1504)$, patients who had previously undergone CABG or in whom CABG was to be combined with valvular heart surgery $(n=139)$, and those for whom the date of the coronary angiography was not known $(n=30)$. The final sample consisted of 457 PTCA patients and 564 CABG patients.

In the Netherlands, we prospectively collected data on patients referred for consideration of coronary revascularization to 10 of the 13 heart centers in the Netherlands [14]. Enrollment in the study began between February and September 1992, depending on the center, with the goal of enrolling a consecutive sample of patients from each center. Enrollment at each center was stopped after one quarter of the expected yearly cases were enrolled. Patients who had previously undergone CABG or in whom CABG was to be combined with other surgery were excluded. We enrolled 3980 patients. For this report, we excluded patients for whom it was decided to continue medical management $(n=757)$ since they were not referred for revascularization following coronary angiography. PTCA and CABG candidates who presented with a condition other than chronic stable angina $(n=1232)$ or with concurrent non-cardiac terminal disease $(n=11)$ were also excluded. Our final sample included 919 PTCA patients and 1061 CABG patients. For analyses of waiting time, which were restricted to patients who actually underwent the procedure to allow comparability with the other datasets, we excluded patients for whom 
either the date of their coronary angiography or coronary revascularization procedure was missing $(n=38)$, and patients who were switched to medical therapy $(n=75)$, dropped out of the study $(n=5)$ or died $(n=13)$ leaving 869 PTCA patients and 980 CABG patients.

In Sweden, we prospectively collected data on patients referred for consideration of coronary revascularization to seven of the eight public Swedish heart centers. We enrolled patients between September 1, 1994 through January 15, 1995 for 6 centers and May through October 1994 for one center, with the goal of enrolling a consecutive sample of at least 2400 patients. Patients who had previously undergone $\mathrm{CABG}$ or in whom $\mathrm{CABG}$ was to be combined with other surgery were excluded. We enrolled 2878 patients. For this report, we also excluded patients for whom it was decided to continue medical management $(n=730)$; those who were judged too ill, by their physician, to participate $(n=47)$, and those presenting with conditions other than chronic stable angina $(n=615)$. Our final sample included 447 PTCA patients and 1039 CABG patients. For analyses of waiting time, we excluded patients for whom either the date of their coronary angiography or coronary revascularization procedure was missing $(n=9)$ and patients who withdrew from the list $(n=45)$ or who died $(n=8)$ leaving 423 PTCA patients and 1001 CABG patients.

\subsection{Data collection and analysis}

Similar abstraction forms were created for each of the three sites to collect each patient's relevant clinical and laboratory information. Data included the patients sociodemographic characteristics, the extent of coronary artery disease and clinical features. In New York State, data were collected retrospectively while in Sweden and the Netherlands prospective data collection began at the first meeting in the heart center in which the patients case was discussed following coronary angiography. Data were reviewed for completeness and accuracy before being entered into the computerized data base. Additional details regarding the way cases were selected, data collected and confidentiality maintained are described elsewhere [13-15].

Waiting time was defined as the number of days between the date of coronary angiography and the date of CABG or PTCA. Data regarding adverse events (e.g., death and complications) that occurred on the waiting list are available for the Netherlands and Sweden. No data on adverse waiting list events are available for New York State patients since the New York data were collected retrospectively and only included those patients who underwent PTCA and CABG; consequently, patients who died while waiting for PTCA or CABG can not be identified.

We used the STATA (version 5.0) statistical package for all analyses. Categorical variables were analyzed by the Chi-square test. We use nptrend, which is an extension of the Wilcoxon rank-sum test, to test for trend across ordered groups [17]. As waiting times were not normally distributed, we report the median waiting time, show the interquartile range $(25-75 \%)$, and test whether the median waiting times were equivalent between groups using the Kruskal-Wallis statistic. To test 
which pairs of groups have different waiting times when the Kruskal-Wallis statistic indicated an overall difference, we use the Dunn Procedure [18]. To see if there was a significant difference in time to death for patients on the waiting list, we compared survival curves for equality using the Mantel-Haenszel test.

\section{Results}

We studied the care received by 1021 patients in New York State, 1424 patients in Sweden and 1849 patients in the Netherlands who underwent CABG or PTCA (Table 1). In New York State, almost one-quarter of all PTCAs were performed in patients younger than age 50 compared with $17 \%$ of such procedures in Sweden and the Netherlands $(P=0.03)$. For bypass surgery, a greater proportion of procedures were performed in patients over the age of 75 in New York State (12\%) compared with Sweden and the Netherlands ( $9 \%$ and $8 \%$, respectively; $P=0.01)$. There was no significant difference between the three sites in the proportion of patients who were women; they represented approximately one-quarter of the patients undergoing PTCA and one-fifth of those undergoing bypass surgery.

\subsection{Waiting time for PTCA}

Patients undergoing PTCA in New York State waited a median of 13 days compared with 42 and 35 days, respectively $(P<0.001)$, for Swedish and Dutch patients (Table 2). There was a linear trend toward decreasing waiting time with increasing age in the Netherlands $(P=0.01)$, with the median wait decreasing from 38 days for patients under the age of 65 , to 16 days for those of 75 years or older, but not for the other two sites. Although women waited for fewer days compared with men in the Netherlands, this finding was not significant. In the Netherlands, patients with more severe angina (i.e., Canadian Cardiovascular Society Class III or IV) had shorter waiting times than those with milder angina $(P<0.01)$ with the median waiting time decreasing from 50 to 30 days.

\subsection{Waiting time for $C A B G$}

Although patients undergoing bypass surgery waited longer than those undergoing PTCA at all three sites (Table 3), this was significant only in Sweden where their median waiting time $40 \%$ longer $(P<0.001)$ and in the Netherlands where they waited twice as long $(P<0.001)$. Bypass patients in New York State waited only 17 days compared with 59 days in Sweden $(P<0.001)$ and 72 days in the Netherlands $(P<0.001)$. Waiting time decreased with age in both New York State $(P<0.05)$ and the Netherlands $(P<0.01)$. Patients with left main coronary artery disease had the shortest waiting times but these patients waited about three times longer for their procedures in Sweden (34 days) and the Netherlands (21 days) than in New York State (6 days; $P<0.01$ for both comparisons). We found no difference in waiting times between patients with three vessel disease and those with one or two 


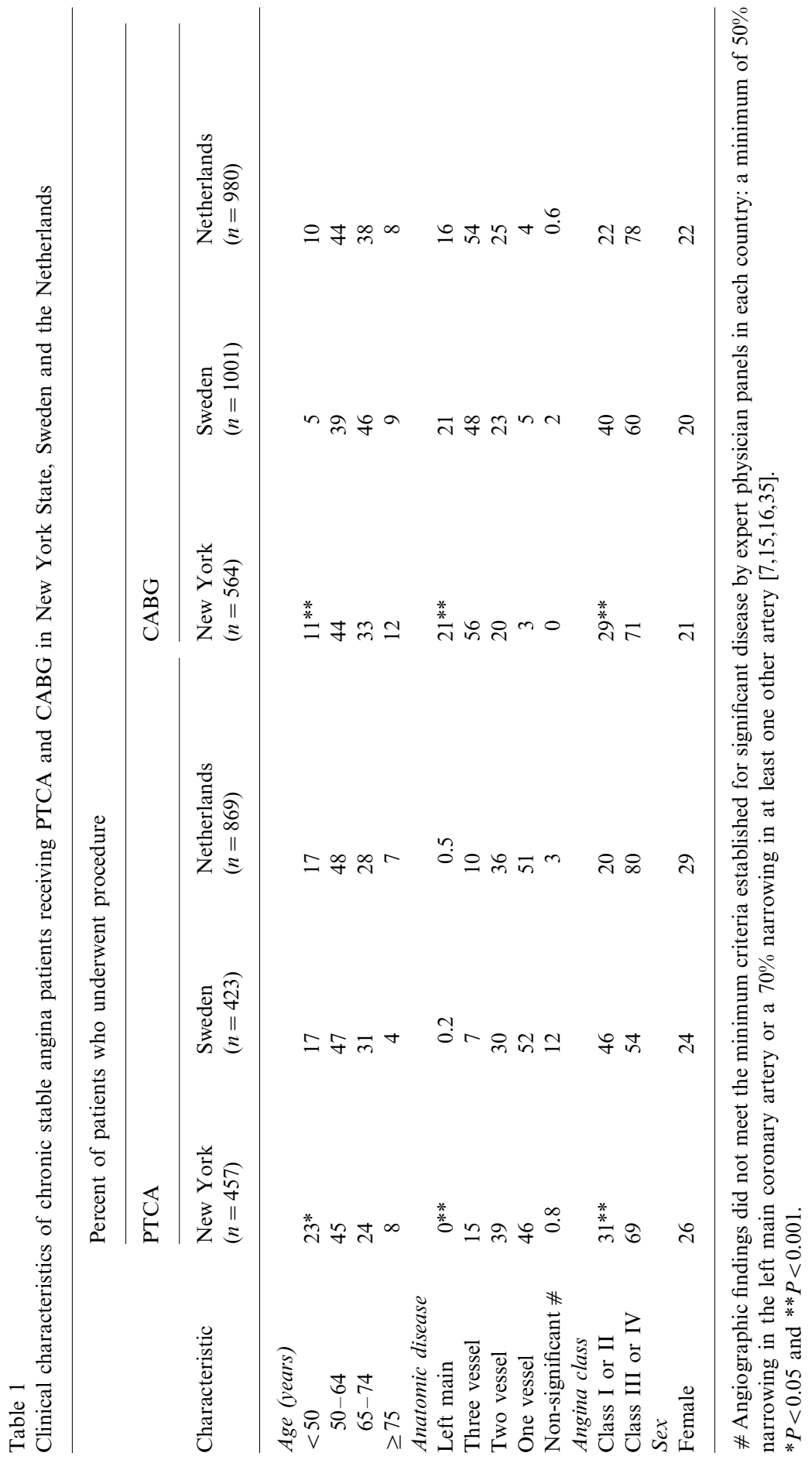


vessel disease at any of the sites. Angina class was a significant factor in waiting time only for Dutch patients. Those with more severe angina waited approximately 30 days less than those with milder angina $(P<0.01)$.

\subsection{Adverse events on waiting lists}

In this section we review the adverse events that occurred to Swedish and Dutch patients on the waiting list. Unfortunately, since the New York State data were collected retrospectively, we have no relevant information for New York patients.

In Sweden, eight of the 1039 candidates for bypass surgery died while waiting for the procedure but none of the 447 referred for PTCA died. Of the patients who died, seven had a cardiac related event. Two of these patients had left main disease, five had three vessel disease, and one had two vessel disease. At the time the patients were reviewed for revascularization, their physicians estimated the urgency of bypass surgery; however, there were no formal guidelines for selection of patients for revascularization or for determining waiting list priority. Patients were classified as needing bypass surgery within one week, between 1 and 4 weeks or between 1 and 3 months. Two patients died after waiting longer than their assigned urgency rating: one was classified as needing bypass surgery within 4 weeks and died on day

Table 2

Median number of days of waiting for chronic stable angina patients undergoing PTCA by site

\begin{tabular}{|c|c|c|c|c|c|c|}
\hline \multirow[t]{2}{*}{ Characteristic } & \multicolumn{2}{|c|}{ New York State } & \multicolumn{2}{|l|}{ Sweden } & \multicolumn{2}{|c|}{ Netherlands } \\
\hline & Median & $(25,75)^{\mathrm{a}}$ & Median & $(25,75)^{\mathrm{a}}$ & Median & $(25,75)^{\mathrm{a}}$ \\
\hline Overall* & 13 & $(3,42)$ & 42 & $(20,63)$ & 35 & $(11,71)$ \\
\hline \multicolumn{7}{|l|}{ Age (years) } \\
\hline$<50$ & 10 & $(2,35)$ & 35 & $(15,61)$ & 38 & $(12,76)^{* *}$ \\
\hline $50-64$ & 16 & $(4,47)$ & 42 & $(21,62)$ & 38 & $(13,76)$ \\
\hline $65-74$ & 12 & $(3,35)$ & 48 & $(19,67)$ & 30 & $(9,64)$ \\
\hline$\geq 75$ & 11 & $(3,36)$ & 42 & $(29,73)$ & 16 & $(8,64)$ \\
\hline \multicolumn{7}{|l|}{ Sex } \\
\hline Male & 13 & $(3,41)$ & 41 & $(19,61)$ & 37 & $(13,76)$ \\
\hline Female & 14 & $(3,50)$ & 48 & $(29,79)$ & 26 & $(8,62)$ \\
\hline \multicolumn{7}{|l|}{ Anatomic disease } \\
\hline Left main & - & $(-)$ & 29 & $(-)$ & 7 & $(2,22)$ \\
\hline Three vessel & 18 & $(5,53)$ & 45 & $(20,79)$ & 36 & $(10,71)$ \\
\hline One or two vessel & 12 & $(3,41)$ & 42 & $(19,61)$ & 34 & $(11,71)$ \\
\hline $\begin{array}{l}\text { Non-significant } \\
\text { Angina class }\end{array}$ & 75 & $(28,124)$ & 51 & $(28,80)$ & 53 & $(12,85)$ \\
\hline Class I or II & 15 & $(6,45)$ & 48 & $(24,71)$ & 50 & $(21,86)^{* * *}$ \\
\hline Class III or IV & 12 & $(3,36)$ & 42 & $(16,59)$ & 30 & $(9,68)$ \\
\hline
\end{tabular}

${ }^{\mathrm{a}}$ Interquartile range.

${ }^{*} P<0.001$ (New York State vs. Sweden; New York State vs. the Netherlands).

$* * P=0.01$ (Netherlands: decreasing waiting time with age (by nptrend)).

${ }^{* * *} P<0.01$ (Netherlands: Canadian Cardiovascular Society Angina Class I/II vs. III/IV). 
Table 3

Median number of days of waiting for chronic stable angina patients undergoing CABG by site

\begin{tabular}{|c|c|c|c|c|c|c|}
\hline \multirow[t]{2}{*}{ Characteristic } & \multicolumn{2}{|c|}{ New York State } & \multicolumn{2}{|l|}{ Sweden } & \multicolumn{2}{|c|}{ Netherlands } \\
\hline & Median & $(25,75)^{\mathrm{a}}$ & Median & $(25,75)^{\mathrm{a}}$ & Median & $(25,75)^{\mathrm{a}}$ \\
\hline $\begin{array}{l}\text { Overall } \\
\text { Age (vears) }\end{array}$ & 17 & $(6,41)^{*}$ & 59 & $(30,91)^{* *}$ & 72 & $(22,122)$ \\
\hline$<50$ & 15 & $(5,45)^{* *}$ & 53 & $(33,84)$ & 82 & $(24,139) * * *$ \\
\hline $50-64$ & 20 & $(7,41)$ & 62 & $(31,93)$ & 78 & $(33,123)$ \\
\hline $65-74$ & 15 & $(6,42)$ & 57 & $(31,85)$ & 66 & $(17,122)$ \\
\hline$\geq 75$ & 10 & $(4,30)$ & 56 & $(25,98)$ & 38 & $(18,86)$ \\
\hline \multicolumn{7}{|l|}{$\overline{S e x}$} \\
\hline Male & 16 & $(6,40)$ & 60 & $(33,91)$ & 72 & $(22,120)$ \\
\hline Female & 20 & $(7,46)$ & 53 & $(26,91)$ & 72 & $(19,128)$ \\
\hline \multicolumn{7}{|l|}{ Anatomic disease } \\
\hline Left main & 5 & $(2,17) \dagger$ & 34 & $(17,63) \dagger$ & 21 & $(10,64) \dagger$ \\
\hline Three vessel & 21 & $(8,42)$ & 66 & $(36,94)$ & 86 & $(36,131)$ \\
\hline One or two vessel & 24 & $(8,61)$ & 68 & $(35,95)$ & 78 & $(22,126)$ \\
\hline Non-significant & - & - & 78 & $(49,98)$ & 85 & $(55,204)$ \\
\hline \multicolumn{7}{|l|}{ Angina class } \\
\hline Class I or II & 17 & $(6,42)$ & 60 & $(30,90)$ & 96 & $(42,133) \ddagger$ \\
\hline Class III or IV & 18 & $(5,40)$ & 57 & $(30,91)$ & 64 & $(19,116)$ \\
\hline
\end{tabular}

${ }^{\text {a Interquartile range. }}$

${ }^{*} P<0.001$ (New York State vs. Sweden; New York State vs. Netherlands).

$* * P<0.01$ (Netherlands vs. Sweden).

$* * * P<0.01$ (Netherlands: decreasing waiting time with age (by nptrend)).

$\dagger P<0.01$ (New York State, Sweden and the Netherlands: left main vs. non-left main disease).

$\$ P<0.01$ (Netherlands: Canadian Cardiovascular Society Angina Class I/II vs. III/IV).

48; the second was to be treated within 3 months and died on day 119 . The remaining six patients died before the maximum recommended waiting time.

In the Netherlands, 11 of the 1061 chronic stable angina candidates for bypass surgery died. Eight of these patients had an established cardiac related event. One of these patients had left main disease, five had three vessel disease and two had two vessel disease. Patients were classified as needing bypass surgery within one day, one week, between 1 and 4 weeks or between 1 and 3 months. Two patients classified as needing bypass surgery within 3 months died after waiting 116 and 176 days, respectively. The remaining patients died before their maximum recommended waiting time. There was no significant difference in the time to death between Dutch and Swedish patients $(P=0.49)$.

An additional eight Dutch patients suffered a non-fatal myocardial infarction, 65 patients had worsening of their angina and 26 had improvement of their anginal symptoms. Some patients urgency status was reclassified due to a change in their symptoms. For example, the number of bypass candidates considered emergencies more than doubled from the time patients were placed on the list (from seven to 17) and there was a $25 \%$ increase in the number of bypass cases considered urgent (from 239 to 296). Overall, for $9 \%$ of Dutch CABG candidates the urgency rating was changed. 
For PTCA, two of the 919 Dutch candidates died and four suffered a non-fatal myocardial infarction while waiting for the procedure. Thirty-one patients had improvement of their angina and 34 had worsening of their angina. Only three PTCA candidates had their urgency status changed to emergent and 27 were reclassified as urgent while waiting. Overall, for $5 \%$ of the PTCA candidates the urgency rating was changed.

\section{Discussion}

There are two major findings from this study. First, waiting times for PTCA and CABG were significantly shorter in New York State than in Sweden and the Netherlands. Second, there were few adverse events among those patients put on a waiting list for PTCA but one percent of those waiting for bypass surgery died.

Why do the waiting times differ to such a degree between countries? There are at least three potential factors that could account for these differences including:

1. a differential effect of patient clinical characteristics on waiting time;

2. the accessibility of health care and the capacity to perform coronary revascularization; and

3. consumer and physician attitudes.

Patients with left main coronary artery disease had significantly shorter waiting times at all three sites, but increased anginal severity only affected waiting times for Dutch patients, where a worsening of angina from Class I or II to Class III or IV led to a $40 \%$ decrease in waiting time for both PTCA and CABG. Age also had a differential effect on waiting time, with decreasing waiting time with increasing age for both Dutch and New York CABG patients and in Dutch PTCA patients. Thus, cross-national differences in the weight given these clinical characteristics may explain partly the differences in waiting time.

Was access similar at these three sites? No. Many Americans are either uninsured or underinsured. In a 1993 poll it was found that $12 \%$ could not get medical care in the previous year and 30\% delayed seeking medical care because they could not afford it [19]. Five percent of US physicians reported that they had difficulty obtaining complex surgical procedures, such as $\mathrm{CABG}$, for their patients at least three times in 1991 [20]. The two most common reasons cited were lack of health insurance to cover payment and that the patients could not afford the health care costs. In contrast, there were no financial barriers to health care in Sweden and the Netherlands. However, merely having access to a health care system doesn't assure patients of access to high-technology procedures such as PTCA and CABG since the number of cardiothoracic surgical units, and therefore treatment capacity, was limited by the government at all three sites [21-23]. There was one cardiothoracic center for every 580000 people in New York State compared with one center for every one million people in Sweden and one for every 1.15 million people in the Netherlands. There were also higher utilization rates for cardiovascular procedures such as bypass surgery in New York State (92 per 100 000) compared with Sweden (79 per 100000 ) and the Netherlands (61 per 100000) [22,24]. Thus, treatment 
capacity was substantially higher in New York State given their respective utilization rates and this may help explain why the waiting list was comparably short there.

A third possible reason for differences in waiting time relates to consumer and physician attitudes towards waiting and health care expenditures. American patients and physicians may be more reluctant to wait than their European counterparts. Almost $60 \%$ of Americans thought it was essential or very important to get elective surgery, such as coronary revascularization for chronic stable angina, without much delay whereas $72 \%$ of Dutch physicians and consumers thought waiting lists are acceptable, at least sometimes, to regulate access to medical services $[19,25]$. With respect to health care expenditures, $69 \%$ of the American public believed that we are spending too little on health care [26] and 77\% rejected even putting a global budget on health care expenditures or expenditures for high technology goods [19]. In contrast, a 1991 survey in Sweden found that 40\% thought that health care expenditures should be increased while $9 \%$ thought that expenditures should be reduced [27]. The Europeans were more satisfied with their health care system than the Americans. When asked what type of change was needed, almost one-third of Americans thought the US health care system needed to be entirely rebuilt in contrast to about 5\% of Swedish and Dutch citizens [28,29].

The differences in waiting times are clinically important. We found that there was a small but significant risk for those on the bypass surgery queue. For PTCA candidates, the risk of dying on the waiting list was less than $0.2 \%$. However, the mortality rate for bypass surgery candidates was $0.8 \%$ in both the Netherlands and Sweden and the rate of death or non-fatal myocardial infarction among the Dutch patients was $1.8 \%$. In addition, almost $10 \%$ of patients had a change in their symptoms necessitating a change in their urgency status. These rates seem excessive when compared with the operative mortality rate for patients undergoing CABG at the time the data were collected of $2.25 \%$ in the Netherlands [30] and 3.6\% in New York State [31].

Were these patients all appropriate candidates for CABG and PTCA? For bypass surgery, where the risk of adverse events on the waiting list is greatest, the inappropriate rate ranged from 2\% in New York State to $8 \%$ in Sweden, with 5\% of cases inappropriate in the Netherlands. The appropriateness of PTCA was more questionable with about $40 \%$ of cases at each site judged uncertain in appropriateness $[14,15]$ (Swedish Council on Technology Assessment in Health Care, unpublished data).

There are several limitations to this study. Firstly, we have no data on the consequences of waiting for coronary angiography, a procedure that is necessary before considering revascularization. If waiting times for coronary angiography were excessive, many of the patients who might be adversely impacted by a prolonged wait for revascularization would already have suffered the consequences. Secondly, we calculated the waiting time as the period between diagnostic coronary angiography and coronary revascularization. In reality, patients are not placed on a waiting list until after the coronary angiography is reviewed and a decision is made regarding treatment. The overall median difference between the date of 
coronary angiography and the date of the cardiovascular conference where the decision was made to place the patient on the waiting list was 1 day for Swedish PTCA and CABG patients, 4 days for Dutch PTCA patients and 6 days for Dutch CABG patients. Thirdly, we do not have complete data on all adverse events that occurred. In Sweden we only recorded major events such as mortality while in New York, the data were collected retrospectively from those patients who received the procedure and thus we could not study adverse events patients experienced on the queue. Yet, given the relatively short waiting times in New York, the clinical similarity of the patients and the rate of occurrence of adverse events in Sweden and the Netherlands, we doubt that we missed many significant events. We also did not measure indirect effects of queuing such as possible increased anxiety for patients and their families. Fourthly, we studied adverse events in chronic stable angina patients who are at less risk of adverse events then patients with unstable angina or following a myocardial infarction; however, this allowed us to examine a more homogeneous population. Fifthly, we studied waiting times between 1990 and 1994; some of the differences we found might reflect a slower diffusion of technology in Europe than in the United States. Finally, although our sample was representative of the Netherlands and Sweden it may not be representative of the United States. Waiting times and types of patients undergoing CABG and PTCA may differ between New York and other states with less regulatory environments [15,32-34].

This study illustrates the advantage of comparing outcomes of care in different countries to better understand how health care systems affect their citizens. For bypass surgery, Swedish and Dutch patients waited 42 to 55 days more than New York State patients (see Table 3), this wait was associated with a small risk of death or myocardial infarction. However, we did not find a dose-response relationship between waiting time and the probability of dying on the waiting list. Despite the shorter waiting period in New York State, we found that New York patients did not have less severe angina, less coronary artery disease, nor that they had higher rates of inappropriate use. In fact $76 \%$ of the New York patients had left main or three vessel coronary artery disease compared with $69 \%$ and $70 \%$ of patients in Sweden and the Netherlands, respectively.

For PTCA, we also found longer waiting periods in Sweden and the Netherlands but very few patients experienced adverse events because of this wait. However, the patients who appeared to have the least severe disease (milder angina and substantially greater incidence of non-significant coronary artery disease) were from Sweden and not from New York State. Thus the greater capacity to perform these procedures in New York State was not associated with inappropriate resource utilization.

Partly in response to these data the Netherlands have decided to expand bypass surgery capacity [35]. In Sweden and New York State, access to cardiovascular care continues to be closely monitored. Further international cooperation may identify other areas where quality of care may be improved. 


\section{Acknowledgements}

This work was supported in part by The Commonwealth Fund, Morgan Guaranty Trust, the New York Community Trust, the Netherlands Health Insurance Board, the Swedish Medical Research Council and the Swedish Federation of County Councils. The Dutch data were collected as part of DUCAT (The Dutch inventory of invasive coronary artherosclerosis treatments) and the Swedish data were collected as part of SWEDCOR/SBU (The Swedish collaborative study on coronary revascularization, indications, and outcomes). The authors would like to acknowledge assistance provided by the New York State Department of Health. We thank Dr Robert H. Brook, and Seema Sonnad, M.A. for their helpful comments on earlier versions of the manuscript. We also appreciate the assistance of Linda Zhang in data analysis.

\section{References}

[1] Luft HS, Bunker JP, Enthoven AC. Should operations be regionalized? The empirical relation between surgical volume and mortality. New England Journal of Medicine 1979;301(25):1364-9.

[2] Naylor CD, Levinton CM, Baigrie RS, Goldman BS. Placing patients in the queue for coronary surgery: do age and work status alter Canadian specialists' decisions?. Journal of General Internal Medicine 1992;7(5):492-8.

[3] McGregor M, Pelletier G. Planning of specialized health facilities. New England Journal of Medicine 1978;299:179-81.

[4] Finkler SA. Cost-effectiveness of regionalization: The heart surgery example. Inquiry 1979;16:26470.

[5] Kimmel SE, Berlin JA, Laskey WK. The relationship between coronary angioplasty procedure volume and major complications. Journal of the American Medical Association 1995;274:1137-42.

[6] Goldacre MJ, Lee A, Don A. Waiting list statistics I: Relation between admissions from waiting list and length of waiting list. British Medical Journal 1987;295:1105-8.

[7] Eddy D. Rationing resources while improving quality: How to get more for less. Journal of the American Medical Association 1994;272:817-24.

[8] Committee on Choices in Health Care. Choices in Health Care. Zoetermeer, the Netherlands: Ministry of Welfare, Health and Cultural Affairs, 1992.

[9] Bindman AB, Grumbach K, Keanse D, Luce JM. Consequences of queuing for care at a public hospital emergency department. Journal of the American Medical Association 1991;266:1091-6.

[10] Naylor CD. A different view of queues in Ontario. Health Affairs 1991;10:110-28.

[11] Naylor CD, Levinton CM, Baigrie RS. Adapting to waiting lists for coronary revascularization. Do Canadian specialists agree on which patients come first?. Chest 1992;101:715-22.

[12] Carroll RJ, Horn SD, Soderfeldt B, James BC, Malmberg L. International comparison of waiting times for selected cardiovascular procedures. Journal of the American College of Cardiology 1995;25:557-63.

[13] Hilborne LH, Leape LL, Bernstein SJ, et al. The appropriateness of use of percutaneous transluminal coronary angioplasty in New York State. Journal of the American Medical Association 1993;269:761-765.

[14] Meijler AP, Rigter H, Bernstein SJ, et al. The appropriateness of intention to treat decisions for invasive therapy in coronary artery disease in the Netherlands. Heart 1997(77):219-224.

[15] Leape LL, Hilborne LH, Park RE, et al. The appropriateness of use of coronary artery bypass graft surgery in New York State. Journal of the American Medical Association 1993;269:753-760. 
[16] Johansson SR, Brorsson B, Bernstein SJ. Coronary artery bypass graft and percutaneous transluminal coronary angioplasty: A literature review and ratings of appropriateness and necessity. SBU Report No. 120E. Stockholm, Sweden: The Swedish Council on Technology Assessment in Health Care, May 1994.

[17] Cuzick J. A Wilcoxon-type test for trend. Statistics in Medicine 1985;4:87-90.

[18] Rosner B. Fundamentals of biostatistics, 3rd edition. Boston: PWS-Kent Publishing Company, 1990.

[19] Blendon RJ, Hyams TS, Benson JM. Bridging the gap between expert and public views on health care reform. Journal of the American Medical Association 1993;269:2573-2578.

[20] Blendon RJ, Donelan K, Leitman R, et al. Health reform lessons learned from physicians in three nations. Health Affairs (Millwood) 1993;12:194-203.

[21] Ham C. Reforming the Swedish health services: Three different modes of financing and delivering health care scrutiny. British Medical Journal 1994;308:219-20.

[22] Health Council of the Netherlands Committee. Heart Surgery and Interventional Cardiology for Adults. The Hague: Health Council of the Netherlands; publication no. 1995/01E, 1995.

[23] Chassin MR, Hannan EL, DeBuono BA. Benefits and hazards of reporting medical outcomes publicly. New England Journal of Medicine 1996;334:394-398.

[24] New York State Department of Health. Coronary artery bypass surgery in New York State 1991-1993. New York State Department of Health, June 1995.

[25] Tymstra T, Andela M. Opinions of Dutch physicians, nurses, and citizens on health care policy, rationing, and technology. Journal of the American Medical Association 1993;270:2995-2999.

[26] Los Angeles Times Poll. Storrs, Connecticut: Roper Center for Public Opinion Research, 1990.

[27] Bjork S, Rosen P. Setting health care priorities in Sweden: The politician's point of view. Health Policy 1993;26:141-154.

[28] Blendon RJ, Leitman R, Morrison I, Donelan K. Satisfaction with health systems in ten nations. Health Affairs (Millwood) 1990;9:185-192.

[29] Blendon RJ, Benson J, Donelan K, Leitman R, Taylor H, Koeck C, Gitterman D. Who has the best health care system? A second look. Health Affairs (Millwood) 1995;14:220-230.

[30] Centraal Bureau voor de Statistiek. Vademecum Gezondheidsstatistiek (Health statistics Compendium) Nederland 1991. Den Haag: SDU, 1991.

[31] Hannan EL, Kilburn H, O'Donnell JF, Lukacik G, Shields EP. Adult open heart surgery in New York State. An analysis of risk factors and hospital mortality rates. Journal of the American Medical Association 1990;264:2768-2774.

[32] Graves EJ. National Hospital Discharge Survey: Annual Summary, 1992. National Center for Health Statistics. Vital and Health Statistics 1994;13(119).

[33] Tunis SR, Gelband H. Health care technology in the United States. In: Health Care Technology and it's Assessment in Eight Countries. Washington, DC: US Congress, US Government Printing Office, Office of Technology Assessment OTA-BP-H-140, 1995.

[34] Grumbach K. Regionalization of cardiac surgery in the United States and Canada: Outcomes, choice and geographic access. Journal of the American Medical Association 1995;274:1282-8.

[35] Netherlands Minister of Health, Welfare and Sport. Concept - Planningsbesluit hartchirurgie/interventiecardiologie (Draft Planning Proposal for heart surgery and intervention cardiology) Rijswijk, the Netherlands: Ministry of Health, Welfare and Sport, 1996. 